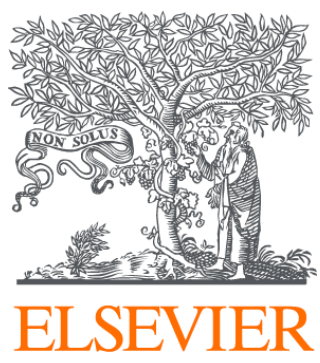

Since January 2020 Elsevier has created a COVID-19 resource centre with free information in English and Mandarin on the novel coronavirus COVID-

19. The COVID-19 resource centre is hosted on Elsevier Connect, the company's public news and information website.

Elsevier hereby grants permission to make all its COVID-19-related research that is available on the COVID-19 resource centre - including this research content - immediately available in PubMed Central and other publicly funded repositories, such as the WHO COVID database with rights for unrestricted research re-use and analyses in any form or by any means with acknowledgement of the original source. These permissions are granted for free by Elsevier for as long as the COVID-19 resource centre remains active. 
Original Contribution

\title{
Strategies for daily operating room management of ambulatory surgery centers following resolution of the acute phase of the COVID-19 pandemic
}

\author{
Franklin Dexter (MD, PhD, FASA) ${ }^{\mathrm{a}, *}$, Mohamed Elhakim (MD) ${ }^{\mathrm{b}}$, Randy W. Loftus (MD) ${ }^{\mathrm{a}}$, \\ Melinda S. Seering (MD) ${ }^{\mathrm{a}}$, Richard H. Epstein (MD, FASA) ${ }^{\mathrm{c}}$ \\ ${ }^{\text {a }}$ University of Iowa, United States of America \\ ${ }^{\mathrm{b}}$ Department of Anesthesia and Critical Care Medicine, Royal Hobart Hospital, Hobart, Tasmania, Australia \\ ${ }^{\mathrm{c}}$ University of Miami, United States of America
}

\section{A B S T R A C T}

We performed a narrative review to explore the economics of daily operating room management decisions for ambulatory surgery centers following resolution of the acute phase of the Coronavirus Disease 2019 (COVID-19) pandemic. It is anticipated that there will be a substantive fraction of patients who will be contagious, but asymptomatic at the time of surgery.

Use multimodal perioperative infection control practices (e.g., including patient decontamination) and monitor performance (e.g., $S$. aureus transmission from patient to the environment). The consequence of COVID-19 is that such processes are more important than ever to follow because infection affects not only patients but the surgery center staff and surgeons.

Dedicate most operating rooms to procedures that are not airway aerosol producing and can be performed without general anesthesia. Increase throughput by performing nerve blocks before patients enter the operating rooms. Bypass the phase I post-anesthesia care unit whenever possible by appropriate choices of anesthetic approach and drugs. Plan long-duration workdays (e.g., 12-h).

For cases where the surgical procedure does not cause aerosol production, but general anesthesia will be used, have initial (phase I) post-anesthesia recovery in the operating room where the surgery was done. Use anesthetic practices that achieve fast initial recovery of the brief ambulatory cases.

When the surgical procedure causes aerosol production (e.g., bronchoscopy), conduct phase I recovery in the operating room and use multimodal environmental decontamination after each case. Use statistical methods to plan for the resulting long turnover times. Whenever possible, have the anesthesia and nursing teams stagger cases in more than one room so that they are doing one surgical case while the other room is being cleaned.

In conclusion, this review shows that while COVID-19 is prevalent, it will markedly affect daily ambulatory workflow for patients undergoing general anesthesia, with potentially substantial economic impact for some surgical specialties.

\section{Introduction}

We recently published a narrative review of infection control and operating room management for the care of patients undergoing surgery during the Coronavirus Disease 2019 (COVID-19) crisis and who are not thought to have COVID-19 [1]. In the current article, we consider these topics for the period when surgery transitions from urgent to essential procedures and, progressively, as queues resolve, to elective surgery [2]. From the many studies published in the intervening weeks, it is apparent that some of the recommendations made can be relaxed for many patients [1].

We limit consideration to ambulatory surgery, expecting that for a considerable time following the peak of SARS-CoV-2 infection, hospital beds often will be occupied with COVID-19 patients [3,4]. The scheduling of surgery requiring inpatient admission will need to consider the constraint of limited intensive care unit and ward beds and the risk to such patients of nosocomial COVID-19 infection [5,6]. There also will be considerations related potentially to the exclusion of visitors, unreliable availability of blood products, and a reduction in the healthcare workforce due to the consequences of the pandemic. However, ambulatory surgery accounts for $74.7 \%$ of surgical cases performed on regular workdays (i.e., non-urgent) $[7,8]$. Essential and highpriority elective surgery that can expand earliest comprise procedures that can be performed safely in free-standing buildings, whether in hospital outpatient departments or at facilities unaffiliated with hospitals [9]. Although we refer to ambulatory "surgery," our intention is for the principles to apply fully to all procedures, whether or not an anesthesia provider is involved in the care of the patient (e.g., includes

* Corresponding author at: Division of Management Consulting, Department of Anesthesia, University of Iowa, 200 Hawkins Drive, 6-JCP, Iowa City, IA 52242, United States of America.

E-mail address: Franklin-Dexter@UIowa.edu (F. Dexter).

URL: https://FranklinDexter.net (F. Dexter). 
brief interventional pain procedures with known efficacy [e.g., single transforaminal epidural steroid injection for new-onset pain]) [10].

\section{Ambulatory surgery: considerations related to presymptomatic and asymptomatic patients}

We assume that RT-PCR nasopharyngeal testing of all ambulatory surgery patients would not be combined with screening computerized tomography of the lung $[11,12]$. There are patients infected with SARSCoV-2 and presymptomatic or asymptomatic [13-19]. A presymptomatic patient has virus present but is not yet manifesting any signs or symptoms of COVID-19. In the asymptomatic patient, radiographic changes (in the lung) are present, but the patient lacks any symptoms or has symptoms attributed to a different process (e.g., occasional cough in a patient with thoracic disease) [15-19]. Recognizing this potential hazard, the "American Association of Nurse Anesthetists, American Society of Anesthesiologists, Anesthesia Patient Safety Foundation, and American Academy of Anesthesiologist Assistants recommend as optimal practice that all anesthesia professionals should utilize personal protective equipment appropriate for aerosol-generating procedures for all patients when working near the airway" $[20,21]$. We presume that all operating room staff (i.e., anesthesia providers, surgeons, and nurses) would be using some version of droplet precautions for all such patients [20,21]. Other authors have discussed the implementation of barrier protection strategies, such as the use of traditional surgical mask and face shield, well fit N95 mask and face shield, etc. For our purposes of considering the economics of ambulatory surgery in the COVID era, we correspondingly partition ambulatory surgery into three categories: (Section 3) no aerosol production by both the surgical procedure and the anesthetic, (Section 4) aerosol production by tracheal intubation and extubation, and (Section 5) aerosol production by the surgical procedure and general anesthetic.

There not only are patients infected with SARS-CoV-2 who are presymptomatic but also asymptomatic patients with radiological changes pathognomonic for COVID-19 [13-19]. Therefore, we expect that all patients undergoing anesthesia will have RT-PCR testing the day before surgery. Early in the disease, viral load is predominantly that of the upper airway (nasopharynx, oropharynx) [22,23]. RT-PCR testing of the oropharynx (subsequently referred to as "COVID-19 testing") has high sensitivity [22,23]. The negative predictive value probably is effectively $99.9 \%$, and patients would be receiving topical viral decolonization preoperatively (see Section 3). Therefore, we expect limited economic effects of COVID-19 from presymptomatic and asymptomatic patients not undergoing general anesthesia. However, during progression of the disease, there is a substantive false negative rate of oropharyngeal testing observed clinically [24-27]. Bronchoalveolar lavage specimens have detectable SARS-CoV-2 for more samples (93\%) than sputum (72\%), and much more than oropharyngeal swabs (32\%) [28]. Consequently, as we address in Sections 4 and 5, we expect large economic effects of COVID-19 from patients receiving general anesthesia.

\section{Ambulatory surgery without aerosol production, without general anesthesia}

This section applies to patients (a) undergoing procedures without airway aerosol production (e.g., excluding interventional pulmonary and upper gastrointestinal endoscopy) [29-31] and (b) receiving local anesthesia, monitored anesthesia care, and/or regional anesthesia including peripheral and spinal blocks with moderate sedation. Consequently, there would not be a need for airborne precautions [31]. Restricting many operating rooms from aerosol producing surgical procedures and general anesthesia would be practical because ambulatory surgery visits in the USA in 2006 were performed without general anesthesia for $69 \%$ of visits [32]. Anesthetics performed without general anesthesia accounted for $72 \%$ (SE 2\%) of the anesthesia minutes among ambulatory surgery procedures performed in the USA in 2010 with an anesthesiologist and/or nurse anesthetists [33]. These statistics are functional overestimates because some aerosol producing procedures (e.g., upper gastrointestinal endoscopy) [30] are coded as being monitored anesthesia care even though the patient is "deeply" sedated for at least a portion of the procedure. Nevertheless, the point is that more than half of ambulatory surgery is performed without general anesthesia. There also are many common interventional procedures performed with local anesthesia alone, again with interventional pain procedures as examples [34,35]. For this review, we reanalyzed the 2010 national survey data to find that $18 \%$ (SE $2 \%$ ) of the ambulatory procedure room time was performed without an anesthesiologist or nurse anesthetist [36].

During anesthesia, bacterial and viral contamination of the anesthesia workspace routinely occurs, largely due to activities of the anesthesiologist and/or nurse anesthetist caring for the patient throughout the case [1,37-40]. Multiple steps can be followed to mitigate this risk, as follows. (a) Decolonize patients using preprocedural chlorhexidine wipes, two doses of nasal povidone-iodine [41] within $1 \mathrm{~h}$ of incision, and chlorhexidine mouth rinse [42-47]. In the unlikely event of an upper respiratory sample for COVID-19 being false negative among patients with presymptomatic disease, SARS-CoV-2 will have been inactivated [48]. (b) Designate and maintain clean and dirty areas [49]. (c) Place alcohol-based hand rubs on the intravenous pole to the left of the provider - spatial orientation matters [50]. (d) Place a wire basket lined with a zip closure plastic bag on the intravenous pole to the right of the provider, for deposit of contaminated instruments (e.g., laryngoscope blade and handle) [49]. (e) Create a closed lumen intravenous system and use hub disinfection [51,52]; prevent bacterial infection and coronavirus viremia [53]. (f) Double glove before touching the patient's nose/mouth and remove the outer glove following contact (e.g., placement of a nasal cannula) [54-56]. (g) After patient positioning, wipe down equipment and high-touch surfaces with disinfection wipes that contain a quaternary ammonium compound and alcohol [40,49,56-59]. (h) Provide data feedback by surveillance of Enterococcus, Staphylococcus aureus, Klebsiella, Acinetobacter, Pseudomonas, and Enterobacter spp. (ESKAPE) transmission to provide feedback on the application of these basic preventive measures [60-62]. These processes $(a-h)$ are known because they significantly reduce the transmission of pathogenic bacteria and viruses [37-40,42-45,49-52,54,55,63]. They are important, but not unique to COVID-19. As an illustrative example, orthopedic surgery under spinal blockade neither produces aerosol from the nose/throat nor uses general anesthesia, yet patient nasal decontamination reduces surgical site infections [46]. The consequence of COVID-19 is that they are more important than ever to follow, because infection affects not only the patients but also the ambulatory surgery center staff and surgeons.

Procedures performed without general anesthesia can be facilitated to increase daily surgical caseload and therefore reduce surgical queues. Management strategies include case scheduling for surgeons to have days with only monitored anesthesia care or regional anesthesia [64]. Using block areas with registered nurses trained to assist with regional anesthesia reduces operating room time and increases throughput [65-72]. The use of peripheral regional anesthesia reduces how long patients stay in the phase I post-anesthesia care unit $[69,73,74]$ and their time to discharge [75]. Monitored anesthesia care also facilitates bypass of the phase I post-anesthesia care unit [76-78]. This quicker discharge and greater throughput can thereby facilitate surgeons completing more cases per day and thereby provide care to more patients.

There may be constraints on performing ambulatory surgery due to inadequate supplies of personal protective equipment. Potentially, some anesthesia machines may be out of service awaiting terminal decontamination due to their use for COVID-19 patients who developed respiratory failure. However, sedation, peripheral nerve blocks, and spinal anesthetics can be performed safely, although not ideally, in the 
absence of an anesthesia machine. Regardless, essential surgery needs to be completed. To reduce the progressively growing surgical queues, shifts should be as long as reasonable (e.g., $12 \mathrm{~h}$ ) [1]. Considerable data show that with this approach, ambulatory surgery centers have underutilized capacity; extending working hours to 5 PM or 7 PM would contribute substantively to reducing the national surgical queues, which are progressively growing. The United States' 2010 national ambulatory surgery survey included outpatient surgery performed at hospitals and unaffiliated free-standing surgery centers [36]. There was $64 \%$ (SE 1\%) of all operating room time completed before 12 noon, and 90\% (SE 1\%) before 3:00 PM [36]. Data for all surgery in hospitals in Iowa 2013 through 2015 were studied [79]. Among the 117 hospitals, on days when a surgeon performed at least one ambulatory surgery case, they performed only 1 or 2 cases total for $77 \%$ (SE $2 \%$ ) of such days and just 1 case for 54\% (SE 2\%) [79]. This shows available capacity for more surgery because those single cases were of brief duration (e.g., the most common being "repair initial inguinal hernia, age 5 years or older, reducible") [79].

\section{Ambulatory surgery without aerosol production, with general anesthesia}

As context, from above, general anesthesia was provided in $31 \%$ of ambulatory surgery visits in the USA in 2006 [32]. General anesthetics accounted for $28 \%$ (SE $2 \%$ ) of the anesthesia minutes among ambulatory surgery procedures performed in the USA in 2010 with an anesthesiologist and/or Certified Registered Nurse Anesthetist [33]. This section does not apply to surgical procedures with airway aerosol production (e.g., thoracic surgery).

The infection control steps summarized in Section 3 apply. After tracheal intubation, deposit the laryngoscope blade and handle in the designated wire basket [49]. Double glove before intubation and remove the outer glove after depositing the blade [54-56]. Because a multimodal bundle alone (a-g) is insufficient for infection control, monitor $S$. aureus transmission for data feedback and to mitigate intervention fatigue [40]. Use a standard behavioral methodology [63] that works in the high task density and fast-paced operating room environments $[50,80]$, and provide feedback that further reduces transmission events [40]. The optimization of this sampling is known [81].

SARS-CoV-2 is transmitted through respiratory droplets (e.g., coughing, sneezing), causing environmental contamination [82]. There are patients with minimal or ambiguous symptoms (e.g., occasional cough) but harboring SARS-CoV-2 in their respiratory system based on radiological imaging [13-19]. Estimated false-negative rates of oropharyngeal testing, based on patients with disease diagnosed by chest computerized tomography, are $17 \%(6 / 35)$ [24], 29\% (15/51) [25], $41 \%(413 / 1014)$ [26], and 63\% (384/610) [27]; pooled 48\% (818/ $1710)$. The estimates are heterogeneous because upper airway involvement declines as the disease progresses [22,23]. Bronchioalveolar lavage (93\%) and sputum samples (72\%) have lower false-negative rates than oropharyngeal samples (32\%) [28]. Asymptomatic patients will cause environmental contamination not only during tracheal intubation [83] but also after tracheal extubation.

For example, to apply these results to the University of Iowa's phase I postanesthesia care unit, approximately $1.3 \%$ of the $>1000$ presymptomatic or asymptomatic patients screened for essential procedures have been SARS-CoV-2 positive by RT-PCR. (As context, between March 31 and April 7, there were 33 of the 49 other US states with a greater weekly increase in the incidence per capita of COVID-19 infection [84].) Using a $0 \%$ false-positive rate and a $29 \%$ false negative rate observed clinically [25], less than the pooled value of $48 \%, 1$ patient in 182 would be expected to test negative yet be infected. ${ }^{1}$ SARS-

\footnotetext{
${ }^{1}$ The 1 in 182 patients $=1 /(1-$ negative predictive value). The negative predictive value is $99.45 \%=(1-$ prevalence $) \times$ (specificity of 1.0$) /([1-$
}

CoV-2 is detected on plastic and stainless steel surfaces (e.g., in the phase I post-anesthesia care unit) for 4 days [48]. The University of Iowa's ambulatory surgery center has 12 operating rooms. Based on 4 cases per day per room and $50 \%$ of cases being general anesthetics, approximately $41 \%$ of 4 -day periods would be expected to have at least one exposure event. ${ }^{1}$

Viral pathogen survival on environmental surfaces extends for several days; SARS-CoV-2 can survive for at least 3 days on a variety of materials commonly encountered in ORs (e.g., stainless steel, plastic) [85]. COVID-19 infectivity cannot be accounted for, population-wise, without including environmental contamination [86]. The necessary environmental cleaning $[58,59]$ applies to the area around the patient, including the phase I post-anesthesia care unit. We do not think that ambulatory surgery centers will be able to sustain reporting and contact tracing for all providers and patients exposed to a nurse or anesthesia provider who develops COVID-19 several days after their shift. (For COVID-19, the mean days from infection to symptom onset is 5 days [95\% confidence interval 4 to 7 ] with 95th percentile 12 days [9 to 18]) [87]. The economic implication is that patients should have their initial (phase I) post-anesthesia recovery in the operating room where they had surgery; by "initial" we mean the period of coughing, disorientation, and sometimes bronchospasm right after tracheal extubation [1].

The cost of having patients undergoing initial phase I recovery in the operating room need not be as large as it may seem. Apropos this recommendation, there are very few phase I post-anesthesia care units in Japan [88]. Even for long-duration cases, patients in Japanese hospitals spend vastly less time in the operating room than do patients at hospitals spend in phase I post-anesthesia care units [89]. Ambulatory surgery cases with an anesthesiologist and/or nurse anesthetist are brief, averaging $61 \mathrm{~min}$ (SE $2 \mathrm{~min}$ ) of operating room time by national US survey [36]. The incidences of prolonged times to extubation, meaning end of surgery to tracheal extubation, are negligibly small for cases of such brief duration $[90,91]$. There are multiple studies from the late 1990s and early 2000s on the use of different anesthetic techniques to achieve faster initial recovery for the patient to have a very brief phase I post-anesthesia recovery time [76,92-97]. Anesthesia providers might need to alter some of their routine anesthetic practices accordingly. Regardless, having patients initially recover in operating rooms is a considerable change administratively for ambulatory surgery centers in North America that do not routinely bypass the phase I postanesthesia care unit among their patients undergoing general anesthesia.

\section{Ambulatory surgery with aerosol production, with or without general anesthesia}

For many otolaryngology, gastroenterology, general surgery, oral surgery, interventional pulmonary and thoracic surgery cases, etc., the changes described in the preceding two sections would be necessary. Additionally, there would be multimodal environmental decontamination after each case [1]. This process includes treating operating rooms using a source generating ultraviolet-C $[98,99]$ or equivalently fast technology to supplement personnel cleaning. Usual operating room and recovery cleaning practices, especially for noncritical items, are often inadequate $[58,59,100,101]$. For many ambulatory surgery centers, this will increase turnover times considerably. Regardless, nearly all operating rooms are positively pressurized with respect to the external environment, meaning that contamination is spread away from the operating room table to the walls and exterior, even when doors are

(footnote continued)

prevalence $] \times 1.0+$ prevalence $\times$ false negative rate 0.2941$)$. The prevalence $=1.3 \%$ incidence of positive tests $/(1$ - false negative rate $)$. The $41 \%$ probability of at least one COVID-19 patient due to false positive RT-PCR $=1-$ $(0.9945)^{\wedge}(120$ general anesthetics per week). 
open [102-105].

Statistical methods to help the ambulatory surgery center determine how many housekeepers are needed have been developed and validated [106-109]. These methods are useful in part because they are non-intuitive. First, determine the times of the workday when there are the largest number of unusually long turnovers, using one-hour epochs [106]. Making graphs or tables of the counts by hour will be helpful because the workdays should be far longer than typical before COVID19 for ambulatory surgery centers [36,79]. This increase in the length of the workday will occur because long-shifts reduce the amount of personal protective equipment used and reduce patient queues for care [1]. The graphs and tables help managers determine the times when the largest numbers of housekeepers are needed [106]. Next, each increase in the number of housekeepers and/or turnover teams will be associated with less overall mean minutes that teams work later than planned [107,109] and lesser probability of prolonged turnovers $[107,108]$. However, the relationship is asymptotic such that each increase in the numbers of housekeepers or teams has progressively lesser benefit $[107,109]$. A useful statistic to use for managerial decisions is the mean daily minutes when the number of simultaneous turnovers is exceeding the number of housekeepers or teams [107]. The statistic is related directly to the minutes that teams will work later than planned [107]. The difference is taken in the statistic calculated with and without the addition of 1 more housekeeper or team [107].

As we think will be apparent, the economic effect of COVID-19 on daily operating room management of ambulatory surgery centers after the acute crisis period likely will be for those operating rooms being used for surgery with aerosol production to have the sometimes frustratingly slow performance of hospitals' surgical suites. We think that a good analogy would be the management of cases on Saturdays. The reason is that among US surgical suites on Saturdays, anesthesia and nursing teams often can have each team working in 2 operating rooms, allowing cleaning and setup while they are caring for another patient [8]. We previously published a review article for making operating room management decisions to reduce the hours that staffs work late for use by surgical suites with long ( $\geq 10 \mathrm{~h}$ ) workdays [110]. The methods apply directly. In the current paper, we do not repeat this extensive and fully covered topic [110]. Rather, we make three points useful as ambulatory surgery centers learn how to apply the science.

First, a common challenge in applying principles to achieve maximal operating room utilization balanced versus preventing the hours that teams work late ("over-utilized time") is that different operating room managers reasonably disagree about how much time is worth saving to warrant moving a case from one room to another (e.g., $15 \mathrm{~min}$ or $30 \mathrm{~min})[111,112]$. Such heterogeneity of perspective on decisions can be neglected because turnover times will be $45 \mathrm{~min}$ or longer for most cases.

Second, usually making decisions to reduce the hours that staff work late, while filling the operating rooms, depends on calculating the operating room allocations, meaning the hours into which cases are scheduled $[110,113,114]$. That characteristically would be done by the combination of service and day of the week $[110,113,114]$. This usually is important because there are substantial differences among combinations of service and day of the week [115]. After the peak of the COVID-19 pandemic has subsided, at facilities with a nearly unlimited queue of patients for surgery and with staff working at most $12 \mathrm{~h}$ daily, this mathematics can be skipped. These dual objectives will need to be met while relying on few historical data [116-120] for cases' operating room times by procedure because previously phase I post-anesthesia care was not in the operating rooms. Ambulatory surgery centers (i.e., facilities performing many brief cases) [36] should schedule cases into operating room hours selected by policy (e.g., $11 \mathrm{~h}$ ) calculated for the end of the day to finish reliably by 12-h [121,122]. Case scheduling would pack as much as possible into those hours while not causing over-utilized time [110,112,123].

Third, decision-making to maximize productivity is both difficult and counter-intuitive because of the conditions that will apply for these operating rooms: long workdays, long-duration cases (i.e., including phase I recovery in the room), and long turnover times [110]. Physicians and non-physicians tend to make operating room management decisions based on rules of thumb. Such heuristics perform poorly, and people do not realize the extent to which their case scheduling decisions are suboptimal [108,124-128]. The knowledge and problem-solving skills to make those decisions well are not learned on the job by experience $[108,124-128]$, but rather by study (e.g., a formal course in operating room management) [129-134].

\section{Discussion}

We performed a narrative review of studies to predict the future economic effect of COVID-19 on daily operating room management of ambulatory surgery centers after the acute crisis period ends in their region, but COVID-19 remains prevalent. The review suggests the following targeted strategies for facilities using RT-PCR COVID-19 screening preoperatively but not chest computerized tomography [11,12,15-19]:

- Use multimodal perioperative infection control practices (e.g., including patient decontamination) and monitor performance (e.g., $S$. aureus transmission from a patient to the environment as a marker of behavioral performance). For details, see References [1] and [40], and infographic checklist and videos prepared by the Anesthesia Patient Safety Foundation [135]. These infection control recommendations are unchanged from our initial study [1].

- Dedicate most operating rooms daily to ambulatory procedures that are not airway aerosol producing and do not need general anesthesia [32-36]. Increase throughput of these cases by using block areas with registered nurses to assist in the performance of regional anesthesia [65-72]. Plan long-duration workdays (e.g., $12 \mathrm{~h}$ ) to reduce the impact of personnel exposed to asymptomatic patients with COVID-19, and to reduce the large queues of patients needing essential surgery $[1,136]$. Bypass the phase I post-anesthesia care unit by appropriate choices of anesthetic approach and drugs [73-78]. These recommendations are relaxed from our initial study [1] because of the findings on the timing of viral load in the upper airway and the effectiveness of patient decolonization drugs for inactivating SARS-CoV-2.

- Until a low-risk cure or effective prevention for COVID-19 is discovered, or a safe and widely used vaccine is developed, surgical procedures that do not result in aerosol production, but for which general anesthesia is administered, should have initial phase I postanesthesia recovery in the operating room where the surgery was performed. Consider following anesthetic practices that achieve fast initial recovery [89,92-97].

- When the surgical procedure results in aerosol production (e.g., bronchoscopy), have phase I recovery in the operating room and use multimodal environmental decontamination after each case [1]. Use statistical methods to plan for the long resulting turnover times [106-109]. Whenever possible, have the anesthesia and nursing teams work in more than one room so that they are doing one surgical case while the other room is being cleaned.

Although our paper is limited to ambulatory surgery, we do not think that this is an important limitation. Healthcare exists to provide care to the population of patients. Because one patient is not more important than another, brief duration essential procedures should take precedence over longer ones because more patients will receive care. Ambulatory surgery cases with anesthesiologist or nurse anesthetist are brief, averaging $61 \mathrm{~min}$ (SE $2 \mathrm{~min}$ ) of operating room time and $72 \mathrm{~min}$ (SE $2 \mathrm{~min}$ ) of total recovery time to discharge, by national US survey [36]. Thus, performing cases in ambulatory surgery centers, especially those without general anesthesia, serves the objective of increasing 
societal utility.

When patients have initial phase I post-anesthesia care in the operating room, after general anesthesia or surgery with aerosol production, the anesthesia provider could staff the recovery. That would be logical if they would not go right away to another room to start a case. If they would start another case in another room, the post-anesthesia care unit nurse could come to the room, as done for some regional anesthetics [64]. That would, however, increase exposure of more healthcare workers to each patient during the period of airborne precautions and consume more personal protective equipment [1].

We have not addressed general anesthesia and/or airway aerosolizing surgical procedures among patients who had COVID-19 and subsequently had two negative tests (i.e., the current method to assess that an individual no longer is contagious). We are unaware of sufficient data on developed immunity and its influence on subsequent infection. We do not think that this lack of direct consideration would have an effect, however, on the principles (i.e., this does not represent a practical limitation to our work).

\section{Funding}

This study was funded in part by the Anesthesia Patient Safety Foundation and by the Department of Anesthesia, University of Iowa.

\section{CRediT authorship contribution statement}

Franklin Dexter:Conceptualization, Methodology, Investigation, Resources, Writing - original draft, Writing - review \& editing.Mohamed Elhakim:Investigation, Writing - review \& editing.Randy W. Loftus:Writing - original draft, Writing - review \& editing.Melinda S. Seering:Writing - review \& editing.Richard H. Epstein:Writing - original draft, Writing - review \& editing.

\section{Declaration of competing interest}

The Division of Management Consulting of the University of Iowa's Department of Anesthesia provides consultations to hospitals. Dr. Dexter receives no funds personally other than his salary and allowable expense reimbursements from the University of Iowa and has tenure with no incentive program. He and his family have no financial holdings in any company related to his work, other than indirectly through mutual funds for retirement. Income from the Division's consulting work is used to fund Division research. A list of all the Division's consults is available at https://FranklinDexter.net/Contact_Info.htm. Dr. Loftus reports research funding from Sage Medical Inc., BBraun, Draeger, and Kenall, has one or more patents pending, and is a partner of RDB Bioinformatics, LLC, and 1055 N 115th St \#301, Omaha, NE 68154, a company that owns OR PathTrac, and has spoken at educational meetings sponsored by Kenall and BBraun. Drs. Elhakim, Seering, and Epstein have no disclosures.

\section{References}

[1] Dexter F, Parra MC, Brown JR, Loftus RW. Perioperative COVID-19 defense: an evidence-based approach for optimization of infection control and operating room management. Anesth Analg 2020. https://doi.org/10.1213/ANE. 0000000000004829. ePub.

[2] CMS releases recommendations on adult elective surgeries, non-essential medical, surgical, and dental procedures during COVID-19 response. https://www.cms.gov/ newsroom/press-releases/cms-releases-recommendations-adult-elective-surgeriesnon-essential-medical-surgical-and-dental, Accessed date: 29 March 2020.

[3] Weissman GE, Crane-Droesch A, Chivers C, Luong T, Hanish A, Levy MZ, et al. Locally informed simulation to predict hospital capacity needs during the COVID19 pandemic. Ann Intern Med 2020. https://doi.org/10.7326/m20-1260. ePub.

[4] Moghadas SM, Shoukat A, Fitzpatrick MC, Wells CR, Sah P, Pandey A, et al. Projecting hospital utilization during the COVID-19 outbreaks in the United States. Proc Natl Acad Sci USA ePub. doi:10.1073/pnas.2004064117.

[5] Wang D, Hu B, Hu C, Zhu F, Liu X, Zhang J, et al. Clinical characteristics of 138 hospitalized patients with 2019 novel coronavirus-infected pneumonia in Wuhan,
China. JAMA 2020;323:1061-9.

[6] Sutton D, Fuchs K, D'Alton M, Goffman D. Universal screening for SARS-CoV-2 in women admitted for delivery. NEJM 2020. https://doi.org/10.1056/ NEJMc2009316.

[7] Dexter F, Jarvie C, Epstein RH. Lack of generalizability of observational studies findings for turnover time reduction and growth in surgery based on the state of Iowa, where from one year to the next, most growth was attributable to surgeons performing only a few cases per week. J Clin Anesth 2018;44:107-13.

[8] Dexter F, Epstein RH, Campos J, Dutton RP. US national anesthesia workload on Saturday and Sunday mornings. Anesth Analg 2016;123:1297-301.

[9] Elhag D, Dexter F, Elhakim M, Epstein RH. Many US hospital-affiliated freestanding ambulatory surgery centers are located on hospital campuses, relevant to interpretation of studies involving ambulatory surgery. J Clin Anesth 2018;49:88-91.

[10] Pearson ACS, Dexter F, Epstein RH. Heterogeneity among hospitals in the percentages of all lumbosacral epidural steroid injections where the patient had received 4 or more in the previous year. Anesth Analg 2019;129:493-9.

[11] Mao R, Liang J, Shen J, Ghosh S, Zhu LR, Yang H, et al. Implications of COVID-19 for patients with pre-existing digestive diseases. Lancet Gastroenterol Hepatol 2020. https://doi.org/10.1016/s2468-1253(20)30076-5. ePub.

[12] Rubin GD, Ryerson CJ, Haramati LB, Sverzellati N, Kanne JP, Raoof S, Schluger NW, Volpi A, Yim JJ, Martin IB, Anderson DJ. The role of chest imaging in patient management during the COVID-19 pandemic: a multinational consensus statement from the Fleischner Society. Chest ePub doi:https://doi.org/10.1016/j.chest.2020. 04.003.

[13] Li YK, Peng S, Li LQ, Wang Q, Ping W, Zhang N, et al. Clinical and transmission characteristics of Covid-19- a retrospective study of 25 cases from a single thoracic surgery department. Curr Med Sci 2020. https://doi.org/10.1007/s11596-0202176-2. ePub.

[14] Wei WE, Li Z, Chiew CJ, Yong SE, Toh MP, Lee VJ. Presymptomatic transmission of SARS-CoV-2 - Singapore, January 23-March 16, 2020. MMWR Morb Mortal Wkly Rep 1 April 2020. https://doi.org/10.15585/mmwr.mm6914e1external icon. ePub.

[15] Inui S, Fujikawa A, Jitsu M, Kunishima N, Watanabe S, Suzuki Y, et al. Chest CT findings in cases from the cruise ship "diamond princess" with coronavirus disease 2019 (COVID-19). Radiology: Cardiothoracic Imaging 2020. https://doi.org/10. 1148/ryct.2020200110. ePub.

[16] Meng H, Xiong R, He R, Lin W, Hao B, Zhang L, et al. CT imaging and clinical course of asymptomatic cases with COVID-19 pneumonia at admission in Wuhan, China. J Infect 2020. https://doi.org/10.1016/j.jinf.2020.04.004. ePub.

[17] Wu X, Sun R, Chen J, Xie Y, Zhang S, Wang X. Radiological findings and clinical characteristics of pregnant women with COVID-19 pneumonia. Int J Gynaecol Obstet 2020. https://doi.org/10.1002/ijgo.13165. ePub.

[18] Albano D, Bertagna F, Bertolia M, Bosio G, Lucchini S, Motta F, et al. Incidental findings suggestive of COVID-19 in asymptomatic patients undergoing nuclear medicine procedures in a high prevalence region. J Nucl Med 2020. https://doi. org/10.2967/jnumed.120.246256. ePub.

[19] Hu Z, Song C, Xu C, Jin G, Chen Y, Xu X, et al. Clinical characteristics of 24 asymptomatic infections with COVID-19 screened among close contacts in Nanjing, China. Sci China Life Sci 2020. https://doi.org/10.1007/s11427-0201661-4. ePub.

[20] American Association of Nurse Anesthetists. Since we don't know if a patient is COVID-19 positive, do we treat all patients as positive? https://www.aana.com/ aana-covid-19-resources/covid-19-faqs, Accessed date: 29 March 2020.

[21] AANA, ASA, APSF and AAAA issue joint statement on use of personal protective equipment during COVID-19 pandemic. https://www.aana.com/home/aanaupdates/2020/03/20/aana-asa-and-apsf-issue-joint-statement-on-use-of-personalprotective-equipment-during-covid-19-pandemic, Accessed date: 29 March 2020.

[22] He X, Lau EH, Wu P, Deng X, Wang J, Hao X, et al. Temporal dynamics in viral shedding and transmissibility of COVID-19. Nat Med 2020. https://doi.org/10. 1038/s41591-020-0869-5. ePub.

[23] Wölfel R, Corman VM, Guggemos W, Seilmaier M, Zange S, Müller MA, et al. Virological assessment of hospitalized patients with COVID-2019. Nature 2020. https://doi.org/10.1038/s41586-020-2196-x. ePub.

[24] Long C, Xu H, Shen Q, Zhang X, Fan B, Wang C, et al. Diagnosis of the coronavirus disease (COVID-19): rRT-PCR or CT? Eur J Radiol 2020. https://doi.org/10.1016/ j.ejrad.2020.108961. ePub.

[25] Fang Y, Zhang H, Xie J, Lin M, Ying L, Pang P, et al. Sensitivity of chest CT for COVID-19: comparison to RT-PCR. Radiology 2020. https://doi.org/10.1148/ radiol.2020200432.

[26] Ai T, Yang Z, Hou H, Zhan C, Chen C, Lv W, et al. Correlation of chest CT and RTPCR testing in coronavirus disease 2019 (COVID-19) in China: a report of 1014 cases. Radiology 2020. https://doi.org/10.1148/radiol.2020200642. ePub.

[27] Li Y, Yao L, Li J, Chen L, Song Y, Cai Z, et al. Stability issues of RT-PCR testing of SARS-CoV-2 for hospitalized patients clinically diagnosed with COVID-19. J Med Virol 2020. https://doi.org/10.1002/jmv.25786. ePub.

[28] Wang W, Xu Y, Gao R, Lu R, Han K, Wu G, Tan W. Detection of SARS-CoV-2 in different types of clinical specimens. JAMA ePub doi:https://doi.org/10.1001/ jama.2020.3786.

[29] Culver DA, Gordon SM, Mehta AC. Infection control in the bronchoscopy suite. A review of outbreaks and guidelines for prevention. Am J Respir Crit Care Med 2003;167:1050-6.

[30] Repici A, Maselli R, Colombo M, Gabbiadini R, Spadaccini M, Anderloni A, et al. Coronavirus (COVID-19) outbreak: what the department of endoscopy should know. Gastrointest Endosc 2020. https://doi.org/10.1016/j.gie. 2020.03.019. ePub. 
[31] Ather B, Edemekong PF. Airborne precautions. StatPearlshttps://www.ncbi.nlm. nih.gov/books/NBK531468/, Accessed date: 30 March 2020.

[32] Cullen KA, Hall MJ, Golosinskiy A. Ambulatory surgery in the United States, 2006. Natl Health Stat Rep 2009;11:1-25.

[33] Bayman EO, Dexter F, Laur JJ, Wachtel RE. National incidence of use of monitored anesthesia care. Anesth Analg 2011;113:185-9.

[34] Pearson ACS, Dexter F. Observational study of the distribution and diversity of interventional pain procedures among hospitals in the state of Iowa. Pain Physician 2019;22:e157-70.

[35] Epstein RH, Dexter F, Pearson ACS. Pain medicine board certification status among physicians performing interventional pain procedures in the State of Florida between 2010 and 2016. Pain Physician 2020;23:E7-18.

[36] Dexter F, Epstein RH, Rodriguez LI. Throughout the United States, pediatric patients undergoing ambulatory surgery enter the operating room and are discharged earlier in the day than are adults. PCORM 2019;16:100076.

[37] Loftus RW, Koff MD, Brown JR, Patel HM, Jensen JT, Reddy S, et al. The epidemiology of Staphylococcus aureus transmission in the anesthesia work area. Anesth Analg 2015;120:807-18.

[38] Loftus RW, Dexter F, Robinson ADM. High-risk Staphylococcus aureus transmission in the operating room: a call for widespread improvements in perioperative hand hygiene and patient decolonization practices. Am J Infect Control 2018;46:1134-41.

[39] Loftus RW, Campos JH. The anesthetists' role in perioperative infection control: what is the action plan? Br J Anaesth 2019;124:e475-9.

[40] Loftus RW, Dexter F, Goodheart MJ, McDonald M, Keech J, Noiseux N, et al. Improving basic preventive measures in the perioperative arena to reduce $\mathrm{S}$. aureus transmission and surgical site infections, a randomized trial. JAMA Netw Open 2020;3:e201934.

[41] Safety \& Efficacy Information 3M skin and nasal antiseptic (Povidone-iodine solution $5 \% \mathrm{w} / \mathrm{w}$ [0.5\% available iodine] USP) patient preoperative skin preparation. https://multimedia.3m.com/mws/media/7167880/3m-skin-and-nasalantiseptic-safety-and-efficacy-brochure.pdf, Accessed date: 31 March 2020.

[42] Eggers M, Eickmann M, Zorn Juergen. Rapid and effective virucidal activity of povidone-iodine products against Middle East respiratory syndrome coronavirus (MERS-CoV) and modified Vaccinia virus Ankara (MVA). Infect Dis Ther 2015;4:491-501.

[43] Eggers M. Infectious disease management and control with povidone iodine. Infect Dis Ther 2019;8:581-93.

[44] Bernstein D, Schiff G, Echler G, Prince A, Feller M, Briner W. In vitro virucidal effectiveness of a $0.12 \%$-chlorhexidine gluconate mouth rinse. J Dent Res 1990;69:874-6.

[45] Fehr AR, Perlman S. Coronaviruses: an overview of their replication and pathogenesis. Methods Mol Biol 2015;1282:1-23.

[46] Phillips M, Rosenberg A, Shopsin B, Cuff G, Skeete F, Foti A, et al. Preventing surgical site infections: a randomized, open-label trial of nasal mupirocin ointment and nasal povidone-iodine solution. Infect Control Hosp Epidemiol 2014;35:826-32.

[47] Loftus RW, Dexter F, Parra MC, Brown JR. Importance of oral and nasal decontamination for patients undergoing anesthetics during the COVID-19 era. Anesth Analg 2020. https://doi.org/10.1213/ANE.0000000000004854. ePub.

[48] Chin AWH, Chu JTS, Perera MRA, Hui KPY, Yen HL, Chan MCW, et al. Stability of SARS-CoV-2 in different environmental conditions. The Lancet 2020. https://doi. org/10.1016/S2666-5247(20)30003-3.

[49] Clark C, Taenzer A, Charette K, Whitty M. Decreasing contamination of the anesthesia environment. Am J Infect Control 2014;42:1223-5.

[50] Koff MD, Loftus RW, Burchman CC, Schwartzman JD, Read ME, Henry ES, et al Reduction in intraoperative bacterial contamination of peripheral intravenous tubing through the use of a novel device. Anesthesiology 2009;110:978-85.

[51] Loftus RW, Patel HM, Huysman BC, Kispert DP, Koff MD, Gallagher JD, et al Prevention of intravenous bacterial injection from health care provider hands: the importance of catheter design and handling. Anesth Analg 2012;115:1109-19.

[52] Loftus RW, Brindeiro BS, Kispert DP, Patel HM, Koff MD, Jensen JT, et al. Reduction in intraoperative bacterial contamination of peripheral intravenous tubing through the use of a passive catheter care system. Anesth Analg 2012;115:1315-23.

[53] Chen W, Xu Z, Mu J, Yang L, Gan H, Mu F, et al. Antibody response and viraemia during the course of Severe Acute Respiratory Syndrome (SARS)-associated coronavirus infection. J Med Microbiol 2004;53:435-8.

[54] Birnbach DJ, Rosen LF, Fitzpatrick M, Carling P, Arheart KL, Munoz-Price LS. Double gloves: a randomized trial to evaluate a simple strategy to reduce contamination in the operating room. Anesth Analg 2015;120:848-52.

[55] Loftus RW, Koff MD, Birnbach DJ. The dynamics and implications of bacterial transmission events arising from the anesthesia work area. Anesth Analg 2015;120:853-60.

[56] Munoz-Price LS, Bowdle A, Johnston BL, Bearman G, Camins BC, Dellinger EP, et al. Infection prevention in the operating room anesthesia work area. Infect Control Hosp Epidemiol 2019;40:1-17.

[57] Schmidt E, Dexter F, Hermann J, Godding JD, Hadder B, Loftus RW. Assessment of anesthesia machine redesign on cleaning of the anesthesia machine using surface disinfection wipes. Am J Infect Control ePub https://doi.org/10.1016/j.ajic.2019. 09.016.

[58] Loftus RW, Koff MD, Burchman CC, Schwartzman JD, Thorum V, Read ME, et al. Transmission of pathogenic bacterial organisms in the anesthesia work area. Anesthesiology 2008;109:399-407.

[59] Loftus RW, Brown JR, Koff MD, Reddy S, Heard SO, Patel HM, et al. Multiple reservoirs contribute to intraoperative bacterial transmission. Anesth Analg
$2012 ; 114: 1236-48$.

[60] Loftus RW, Koff MD, Brown JR, Patel HM, Jensen JT, Reddy S, et al. The dynamics of Enterococcus transmission from bacterial reservoirs commonly encountered by anesthesia providers. Anesth Analg 2015;120:827-36.

[61] Loftus RW, Brown JR, Patel HM, Koff MD, Jensen JT, Reddy S, et al. Transmission dynamics of gram-negative bacterial pathogens in the anesthesia work area. Anesth Analg 2015;120:819-26.

[62] Hadder B, Patel HM, Loftus RW. Dynamics of intraoperative Klebsiella, Acinetobacter, Pseudomonas, and Enterobacter transmission. Am J Infect Control 2018;46:526-32

[63] Robinson A, Dexter F, Renkor V, Reddy S, Loftus R. Operating room PathTrac analysis of current intraoperative S. aureus transmission dynamics. Am J Infect Control 2019;47:1240-7.

[64] Smith MP, Sandberg WS, Foss J, Massoli K, Kanda M, Barsoum W, et al. Highthroughput operating room system for joint arthroplasties durably outperforms routine processes. Anesthesiology 2008;109:25-35.

[65] Williams BA, Kentor ML, Williams JP, Figallo CM, Sigl JC, Anders JW, et al. Process analysis in outpatient knee surgery - effects of regional and general anesthesia on anesthesia-controlled time. Anesthesiology 2000;93:529-38.

[66] Russell RA, Burke K, Gattis K. Implementing a regional anesthesia block nurse team in the perianesthesia care unit increases patient safety and perioperative efficiency. J Perianesth Nurs 2013;28:3-10.

[67] Drolet P, Girard M. Regional anesthesia, block room and efficiency: putting things in perspective. Can J Anesth 2004;51:41-4.

[68] Head SJ, Seib R, Osborn JA, Schwarz SK. A "swing room" model based on regional anesthesia reduces turnover time and increases case throughput. Can J Anesth 2011;58:725-32.

[69] Armstrong KP, Cherry RA. Brachial plexus anesthesia compared to general anesthesia when a block room is available. Can J Anesth 2004;51:41-4.

[70] Marjamaa RA, Torkki PM, Hirvensalo EJ, Kirvelä OA. What is the best workflow for an operating room? A simulation study of five scenarios. Health Care Manag Sci 2009;12:142-6.

[71] Brown MJ, Subramanian A, Curry TB, Kor DJ, Moran SL, Rohleder TR. Improving operating room productivity via parallel anesthesia processing. Int $\mathrm{J}$ Health Care Qual Assur 2014;27:697-706.

[72] Friedman DM, Sokal SM, Chang Y, Berger DL. Increasing operating room efficiency through parallel processing. Ann Surg 2006;243:10-4.

[73] Williams BA, Kentor ML, Williams JP, Vogt MT, DaPos SV, Harner CD, et al. PACU bypass after outpatient knee surgery is associated with fewer unplanned hospital admissions but more phase II nursing interventions. Anesthesiology 2002;97:981-8.

[74] Williams BA, Kentor ML, Vogt MT, Vogt WB, Coley KC, Williams JP, et al. Economics of nerve block pain management after anterior cruciate ligament reconstruction: potential hospital cost savings via associated postanesthesia care unit bypass and same-day discharge. Anesthesiology 2004;100:697-706.

[75] Tighe PJ, Brennan M, Moser M, Boezaart AP, Bihorac A. Primary payer status is associated with the use of nerve block placement for ambulatory orthopedic surgery. Reg Anesth Pain Med 2012;37:254-61.

[76] Dexter F, Macario A, Manberg PJ, Lubarsky DA. Computer simulation to determine how rapid anesthetic recovery protocols to decrease the time for emergence or increase the phase I postanesthesia care unit bypass rate affect staffing of an ambulatory surgery center. Anesth Analg 1999;88:1053-63.

[77] Apfelbaum JL, Walawander CL, Grasela TH, Wise P, McLeskey C, Roizen MF, et al. Eliminating intensive postoperative care in same-day surgery patients using shortacting anesthetics. Anesthesiology 2002;97:66-74.

[78] Twersky RS, Sapozhnikova S, Toure B. Risk factors associated with fast-track ineligibility after monitored anesthesia care in ambulatory surgery patients. Anesth Analg 2008;106:1421-6.

[79] Dexter F, Jarvie C, Epstein RH. At most hospitals in the state of Iowa, most surgeons' daily lists of elective cases include only 1 or 2 cases: individual surgeons' percentage operating room utilization is a consistently unreliable metric. J Clin Anesth 2017:42:88-92.

[80] Rowlands J, Yeager MP, Beach M, Patel HM, Huysman BC, Loftus RW. Video observation to map hand contact and bacterial transmission in operating rooms. Am J Infect Control 2014;42:698-701.

[81] Dexter F, Epstein RH, Gostine AL, Penning DH, Loftus RW. Benefit of systematic selection of pairs of cases matched by surgical specialty for surveillance of bacterial transmission in operating rooms. Am J Infec Control 2020. https://doi.org/ 10.1016/j.ajic.2019.09.025. ePub.

[82] Ong SW, Tan YK, Chia PY, Lee TH, Ng OT, Wong MS, et al. Air, surface environmental, and personal protective equipment contamination by severe acute respiratory syndrome coronavirus 2 (SARS-CoV-2) from a symptomatic patient. JAMA 2020. https://doi.org/10.1001/jama.2020.3227. ePub.

[83] Gardiner C, Veall J, Lockhart S. The use of UV fluorescent powder for COVID-19 airway management simulation training. Anaesthesia 2020. https://doi.org/10. 1111 /arnae. 15089.

[84] Centers for Disease Control COVID-19 Response Team. Geographic differences in COVID-19 cases, deaths, and incidence - United States, February 12-April 7, 2020 MMWR Morb Mortal Wkly Rep 2020;69:465-71. https://doi.org/10.15585/ mmwr.mm6915e4.

[85] Van Doremalen N, Bushmaker T, Morris DH, Holbrook MG, Gamble A, Williamson $\mathrm{BN}$, et al. Aerosol and surface stability of SARS-CoV-2 compared with SARS-CoV-1. N Engl J Med 2020. https://doi.org/10.1056/nejmc2004973.

[86] Yang CY, Wang J. A mathematical model for the novel coronavirus epidemic in Wuhan, China. Math Biosci Eng 2020;17:2708-24.

[87] Li Q, Guan X, Wu P, Wang X, Zhou L, Tong Y, et al. Early transmission dynamics in 
Wuhan, China, of novel coronavirus-infected pneumonia. N Engl J Med 2020;382:1199-207.

[88] Sento Y, Suzuki T, Suzuki Y, Scott DA, Sobue K. The past, present and future of the postanesthesia care unit (PACU) in Japan. J Anesth 2017;31:601-7.

[89] Thenuwara KN, Yoshi T, Nakata Y, Dexter F. Time to recovery after general anesthesia at hospitals with and without a phase I post-anesthesia care unit: a historical cohort study. Can J Anesth 2018;12:1296-302.

[90] Dexter F, Bayman EO, Epstein RH. Statistical modeling of average and variability of time to extubation for meta-analysis comparing desflurane to sevoflurane. Anesth Analg 2010;110:570-80.

[91] Agoliati A, Dexter F, Lok J, Masursky D, Sarwar MF, Stuart SB, et al. Meta-analysis of average and variability of time to extubation comparing isoflurane with desflurane or isoflurane with sevoflurane. Anesth Analg 2010;110:1433-9.

[92] Gan TJ, Glass PS, Windsor A, Payne F, Roscow C, Sebel P, et al. Bispectral index monitoring allows faster emergence and improved recovery from propofol, alfentanil, and nitrous oxide anesthesia. BIS Utility Study Group. Anesthesiology 1997;87:808-15.

[93] Song D, Joshi G, White P. Fast-track eligibility after ambulatory anesthesia: a comparison of desflurane, sevoflurane, and propofol. Anesth Analg 1998;86:267-73.

[94] Song D, van Vlymen J, White PF. Is the bispectral index useful in predicting fasttrack eligibility after ambulatory anesthesia with propofol and desflurane? Anesth Analg 1998;87:1245-8.

[95] Song D, White PF. Remifentanil as an adjuvant during desflurane anesthesia facilitates early recovery after ambulatory surgery. J Clin Anesth 1999;11:364-7.

[96] Coloma M, Zhou T, White PF, Markowitz SD, Forestner JE. Fast-tracking after outpatient laparoscopy: reasons for failure after propofol, sevoflurane, and desflurane anesthesia. Anesth Analg 2001;93:112-5.

[97] Fredman B, Sheffer O, Zohar E, Paruta I, Richter S, Jedeikin R, et al. Fast-track eligibility of geriatric patients undergoing short urologic surgery procedures. Anesth Analg 2002;94:560-4.

[98] Pavia M, Simpser E, Becker M, Mainquist WK, Velez KA. The effect of ultraviolet-C technology on viral infection incidence in a pediatric long-term care facility. Am J Infect Control 2018;46:720-2.

[99] Andersen BM, Bånrud H, Bøe E, Bjordal O, Drangsholt F. Comparison of UV-C light and chemicals for disinfection of surfaces in hospital isolation units. Infect Control Hosp Epidemiol 2006;27:729-34.

[100] Pedersen A, Getty Ritter E, Beaton M, Gibbons D. Remote video auditing in the surgical setting. AORN J 2017;105:159-69.

[101] Moore G, Ali S, Cloutman-Green EA, Bradley CR, Wilkinson MAC, Hartley JC, et al. Use of UV-C radiation to disinfect non-critical patient care items: a laboratory assessment of the nanoclave cabinet. BMC Infect Dis 2012;12:174.

[102] Whyte W, Shaw BH, Freeman MA. An evaluation of a partial-walled laminar-flow operating room. J Hyg Camb 1974;73:61-74.

[103] Weiser MC, Shemesh S, Chen DD, Bronson MJ, Moucha CS. The effect of doo opening on positive pressure and airflow in operating rooms. J Am Acad Orthop Surg 2018;26:e105-13.

[104] Alsved M, Civilis A, Ekolind P, Tammelin A, Andersson AE, Jakobsson J, et al. Temperature-controlled airflow ventilation in operating rooms compared with laminar airflow and turbulent mixed airflow. J Hosp Infect 2018;98:181-90.

[105] Sadrizadeh S, Holmberg S. Surgical clothing systems in laminar airflow operating room: a numerical assessment. J Infect Public Health 2014;7:508-16.

[106] Dexter F, Epstein RH, Marcon E, Ledolter J. Estimating the incidence of prolonged turnover times and delays by time of day. Anesthesiology 2005;102:1242-8.

[107] Dexter F, Marcon E, Aker J, Epstein RH. Numbers of simultaneous turnovers calculated from anesthesia or operating room information management system data. Anesth Analg 2009;109:900-5.

[108] Wang J, Dexter F, Yang K. A behavioral study of daily mean turnover times and first case of the day start tardiness. Anesth Analg 2013;116. (1333-1141).

[109] Gul S. A stochastic programming approach for appointment scheduling under limited availability of surgery turnover teams. Serv Sci 2018;10:277-88.

[110] Dexter F, Wachtel RE, Epstein RH. Decreasing the hours that anesthesiologist and nurse anesthetists work late by making decisions to reduce the hours of overutilized operating room time. Anesth Analg 2016;122:831-42.

[111] Dexter F, Smith TC, Tatman DJ, Macario A. Physicians' perceptions of minimum time that should be saved to move a surgical case from one operating room to another: internet-based survey of the Association of Anesthesia Clinical Directors' (AACD) members. J Clin Anesth 2003;15:206-10.

[112] Dexter F, Epstein RD, Traub RD, Xiao Y. Making management decisions on the day of surgery based on operating room efficiency and patient waiting times. Anesthesiology 2004;101:1444-53.

[113] Strum DP, Vargas LG, May JH, Bashein G. Surgical suite utilization and capacity planning: a minimal cost analysis model. J Med Syst 1997;21:309-22.

[114] McIntosh C, Dexter F, Epstein RH. The impact of service-specific staffing, case scheduling, turnovers, and first-case starts on anesthesia group and operating room productivity: tutorial using data from an Australian hospital. Anesth Analg 2006;103:1499-516.

[115] Marcon E, Dexter F. An observational study of surgeons' sequencing of cases and its impact on postanesthesia care unit and holding area staffing requirements at hospitals. Anesth Analg 2007;105:119-26.

[116] Dexter F, Ledolter J. Bayesian prediction bounds and comparisons of operating room times even for procedures with few or no historical data. Anesthesiology 2005;103:1259-67.

[117] Eijkemans MJC, van Houdenhoven M, Nguyen T, Boersma E, Steyerberg EW, Kazemier G. Predicting the unpredictable: a new prediction model for operating room times using individual characteristics and the surgeon's estimate. Anesthesiology 2010;112:41-9.

[118] Dexter F, Ledolter J, Tiwari V, Epstein RH. Value of a scheduled duration quantified in terms of equivalent numbers of historical cases. Anesth Analg 2013;117:204-9.

[119] Luangkesorn KL, Eren-Dogu ZF. Markov chain Monte Carlo methods for estimating surgery duration. J Stat Comput Sim 2016;86:262-78.

[120] Dexter F, Bayman EO, Pattillo JCS, Schwenk ES, Epstein RH. Influence of parameter uncertainty on the tardiness of the start of a surgical case following a preceding surgical case performed by a different surgeon. PCORM 2018;13:12-7.

[121] Dexter F, Yue JC, Dow AJ. Predicting anesthesia times for diagnostic and interventional radiological procedures. Anesth Analg 2006;102:1491-500.

[122] Dexter F, Wachtel RE. Ophthalmologic surgery is unique in operating room management. Anesth Analg 2014;119:1243-5.

[123] Dexter F, Traub RD. How to schedule elective surgical cases into specific operating rooms to maximize the efficiency of use of operating room time. Anesth Analg 2002;94:933-42.

[124] Dexter F, Willemsen-Dunlap A, Lee JD. Operating room managerial decisionmaking on the day of surgery with and without computer recommendations and status displays. Anesth Analg 2007;105:419-29.

[125] Dexter F, Lee JD, Dow AJ, Lubarsky DA. A psychological basis for anesthesiologists' operating room managerial decision-making on the day of surgery. Anesth Analg 2007;105:430-4.

[126] Dexter F, Xiao Y, Dow AJ, Strader MM, Ho D, Wachtel RE. Coordination of appointments for anesthesia care outside of operating rooms using an enterprisewide scheduling system. Anesth Analg 2007;105:1701-10.

[127] Stepaniak PS, Mannaerts GH, de Quelerij M, de Vries G. The effect of the operating room coordinator's risk appreciation on operating room efficiency. Anesth Analg 2009;108:1249-56.

[128] Dexter EU, Dexter F, Masursky D, Garver MP, Nussmeier NA. Both bias and lack of knowledge influence organizational focus on first case of the day starts. Anesth Analg 2009;108:1257-61.

[129] Wachtel RE, Dexter F. Curriculum providing cognitive knowledge and problemsolving skills for anesthesia systems-based practice. J Grad Med Educ 2010;2:624-32.

[130] Ahn PH, Dexter F, Fahy BG, Van Swol LM. Demonstrability of analytics solutions and shared knowledge of statistics and operating room management improves expected performance of small teams in correctly solving problems and making good decisions. PCORM 2020;19:100090.

[131] Dexter F, Masursky D, Wachtel RE, Nussmeier NA. Application of an online reference for reviewing basic statistical principles of operating room management. $J$ Stat Educ 2010;18(3).

[132] Vasilopoulos T, Dexter F, Van Swol LM, Fahy BG. Trust improves during one-day resident operating room management course preceded by directed study of required statistical content. J Clin Anesth 2019;55:43-9.

[133] Dexter F, Van Swol L. Influence of data and formulas on trust in information from journal articles in an operating room management course. A\&A Case Rep 2016;6:329-34.

[134] Dexter F, Epstein RH, Fahy BG, Van Swol LM. With directed study before a 4-day operating room management course, trust in the content did not change progressively during the classroom time. J Clin Anesth 2017;42:57-62.

[135] Anesthesia Patient Safety Foundation. Prevention of perioperative COVID-19 transmission. https://www.apsf.org/wp-content/uploads/news-updates/2020/ Prev-PeriOp-COVID-19-Transm-TW.pdf, Accessed date: 2 April 2020.

[136] Mascha EJ, Schober P, Schefold JC, Stueber F, Luedi MM. Staffing with diseasebased epidemiologic indices may reduce shortage of intensive care unit staff during the COVID-19 pandemic. Anesth Analg 2020. https://doi.org/10.1213/ ANE.0000000000004849. ePub. 